\title{
Guidance for Deployment of Mobile Technologies for Nuclear Power Plant Field Workers
}

Ronald K. Farris

Heather Medema

September 2012

The INL is a U.S. Department of Energy National Laboratory operated by Battelle Energy Alliance 


\section{DISCLAIMER}

This information was prepared as an account of work sponsored by an agency of the U.S. Government. Neither the U.S. Government nor any agency thereof, nor any of their employees, makes any warranty, expressed or implied, or assumes any legal liability or responsibility for the accuracy, completeness, or usefulness, of any information, apparatus, product, or process disclosed, or represents that its use would not infringe privately owned rights. References herein to any specific commercial product, process, or service by trade name, trade mark, manufacturer, or otherwise, does not necessarily constitute or imply its endorsement, recommendation, or favoring by the U.S. Government or any agency thereof. The views and opinions of authors expressed herein do not necessarily state or reflect those of the U.S. Government or any agency thereof. 


\title{
Guidance for Deployment of Mobile Technologies for Nuclear Power Plant Field Workers
}

\author{
Ronald K. Farris \\ Heather Medema
}

September 2012

Idaho National Laboratory Idaho Falls, Idaho 83415

http://www.inl.gov

\author{
Prepared for the \\ U.S. Department of Energy \\ Office of Nuclear Energy \\ Under DOE Idaho Operations Office \\ Contract DE-AC07-05ID14517
}





\section{EXECUTIVE SUMMARY}

This report is a guidance document prepared for the benefit of commercial nuclear power plants' (NPPs) supporting organizations and personnel who are considering or undertaking deployment of mobile technology for the purpose of improving human performance and plant status control (PSC) for field workers in an NPP setting. This document especially is directed at NPP business managers, Electric Power Research Institute, Institute of Nuclear Power Operations, and other non-Information Technology personnel. This information is not intended to replace basic project management practices or reiterate these processes, but is to support decision-making, planning, and preparation of a business case.

\section{Background}

Mobile technologies provide the potential for numerous applications in commercial NPPs, including, but not limited to, real-time and near-time data transfer to and from the field. Deploying this type of technology could significantly improve accuracy in positioning plant components (PPC), the collective situational awareness of plant personnel, and decision-making by providing plant personnel with rich data (e.g., electronic forms, diagrams, video, and voice) in real-time or near-time. Leveraging the latest commercial off-theshelf technology should result in improved human performance and PPC by making the right field worker actions easy and the wrong actions difficult if not impossible. Additional benefits in safety, efficiency, and productivity are highly probable given the broad array of the current and emerging capabilities of the latest mobile technology. However, as with any new technology deployment, consideration should be given to the impact on the station enterprise systems and should be considered a major business decision. To maximize the full benefits of these emerging technologies with minimum risk, a systematic approach to fullscale deployment will be essential.

\section{Objectives}

This document is intended to do the following:

- Provide guidance to NPPs for successful deployment of mobile technologies to improve field worker human performance and efficiency.

- Present a brief overview of current mobile technologies' hardware and software capabilities.

- Support decision-making about deployment of mobile technologies at a commercial NPP.

- Present information that will support the building of a business case for mobile technologies implementation projects to improve human performance and PSC. 
- Present a method to evaluate station needs to create a pull from vendors providing technology versus a push.

\section{Method}

The Light Water Reactor Sustainability (LWRS) Program's research team analyzed the current state of human performance and PSC in NPPs and the latest information on mobile devices and software technology in order to explore a number of usage scenarios. In their research, the team sought to answer three questions regarding improvements in PSC and human performance:

1. Would modern mobile technology, with embedded error prevention tools, increase efficiency, performance, and decision-making, and reduce human error?

2. Would the use of mobile devices improve the task focus of field workers?

3. What impact would mobile technologies have on improving PSC?

\section{Results}

This guidance document presents a high-level approach to addressing PSC using mobile technologies, as well as a basic human performance improvement process to accomplish this task. Additional information about some aspects of mobile technology, specific examples from previous research, and implementation considerations also are provided.

\section{LWRS Human Performance Pilot Project Team Perspective}

Utilization of mobile technologies for rich data transfer to/from the field (such as component status [positioning] data/voice/video/digital photograph/work control and request forms integration, remote equipment monitoring, and work process control) have the potential to vastly improve plant productivity, reliability, and safety. When considered in the context of extending the life of the current reactor fleet, these are critically important benefits. The Human Performance Pilot Project research team has created this guidance document in order to support U.S. NPP managers who are interested in the potential benefits described in this document, while minimizing any potential risks that may occur from deployment of such technology.

In the LWRS Program's research pathway for Advanced Instrumentation, Information, and Control Systems Technologies, a series of pilot projects were defined as the roadmap for industry to collectively integrate new technologies into NPP work activities. A pilot project is an individual demonstration that is part of a larger strategy needed to achieve modernization according to a plan. It is small enough to be undertaken by a single utility, it demonstrates a key technology or outcome required to achieve success in the higher strategy, and it supports scaling that can be replicated and used by other NPPs. The Human Performance Pilot Project was directed at carrying out the applied research for the development and pilot of technology designed to enhance PSC, improve human performance and reliability, and increase overall operational efficiency and safety. 


\section{Keywords}

human performance

mobile technologies

plant status control

situational awareness

operating experience

\section{Milestone Report}

The following report documents completion of the milestone:

M3 LW-12IN060308: Improved Plant Operator Performance in Plant

Configuration Control. The milestone is described as develop guidelines and demonstration technologies for NPP operations and maintenance $(\mathrm{O} \& \mathrm{M})$ work processes.

The Idaho National Laboratory research team demonstrated both operations and maintenance activities at the Catawba Flow Loop Training Facility for Duke Energy personnel, as well as representatives from other prominent energy utilities within the United States.

The tasks completed in February 2012 included a concept demonstration, which included the following:

- Normal operations activity at the Catawba Nuclear Station Flow Loop Training Facility

- Normal maintenance activity in the Catawba Maintenance Training Facility

- An array of mobile technologies that constitute a platform for field activities in an NPP in order to address correct component (correct train/plant) identification through bar code reader procedural linkage between action and component verification and visual concurrent verification by remote operator at the Information Control Center. 


\section{ACKNOWLEDGEMENTS}

The Human Performance Pilot Project research team would like to acknowledge the efforts of the following individuals and organizations which made this research possible:

- Greg Robison, Duke Manager, Fleet Technical Support, for his support in all aspects of setting up the research activities at Catawba Nuclear Station.

- Tom Waicosky, James Robinson, Jeffrey Mize, and other members of the Catawba Nuclear Station training department for their support in building process maps, providing the flow loop materials needed for scenario development, maintenance and operational procedures, and for playing active roles during project demonstration activities.

- Catawba Nuclear Station management and members of the Catawba Nuclear Station for hosting the field demonstration activities.

- Tom Disanto, Idaho National Laboratory Instrumentation and Control Applied Engineer, and Malwina Chaczko, Idaho National Laboratory intern, for their roles in development of the software used in this technology demonstration.

- Dr. Bruce P. Hallbert, Ken D. Thomas, Johanna H. Oxstrand, and Gregory Weatherby of the Idaho National Laboratory Human Factors Group for their insights, expertise, and advice.

- Katya Le Blanc of the Idaho National Laboratory Human Factors Group for her technical review expertise of the final document. 


\section{CONTENTS}

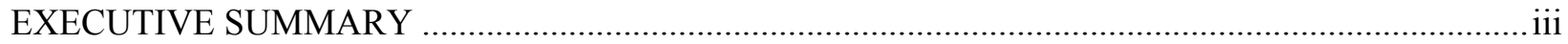

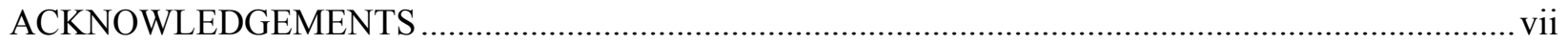

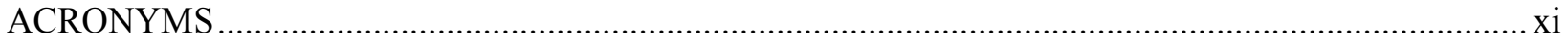

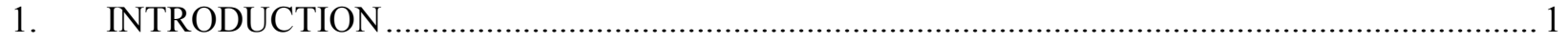

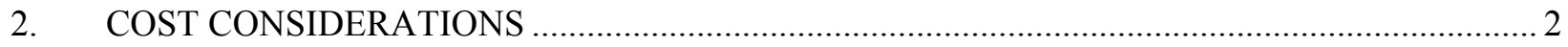

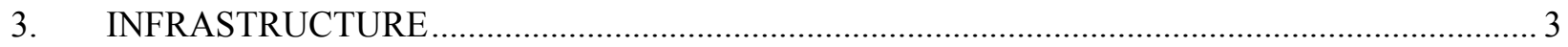

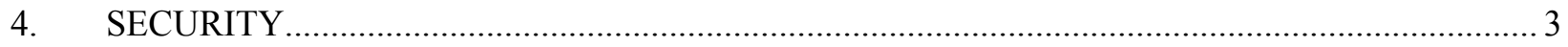

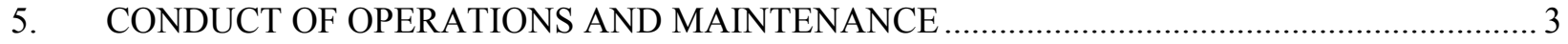

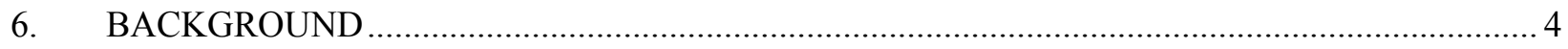

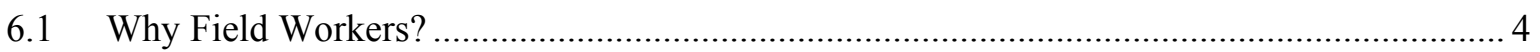

6.1.1 Mobile Technologies for Nuclear Power Plant Field Workers .................................. 4

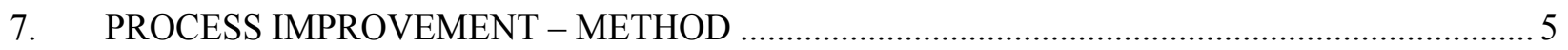

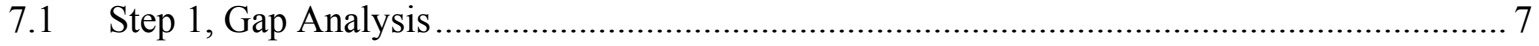

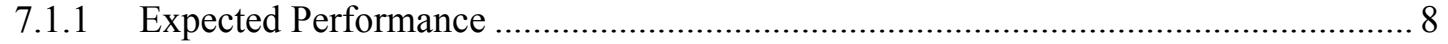

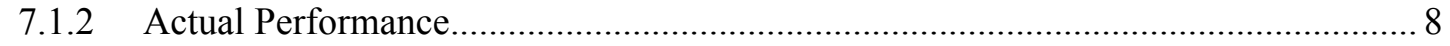

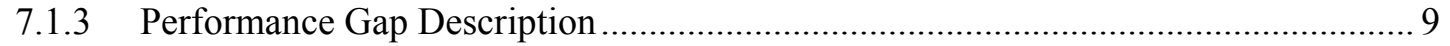

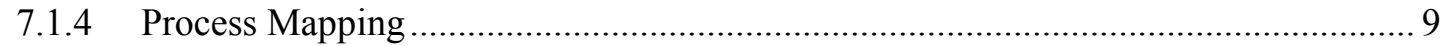

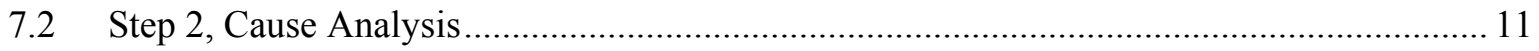

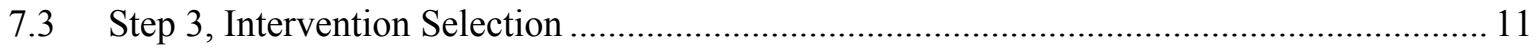

7.3.1 Mobile Technology Software and Hardware .......................................................... 13

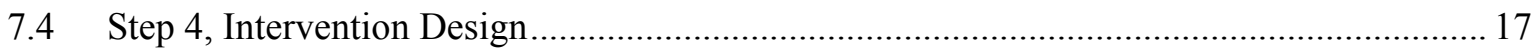

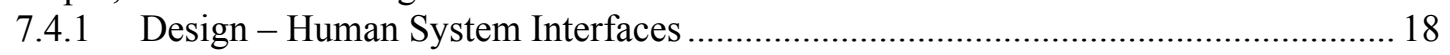

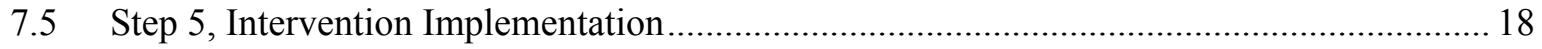

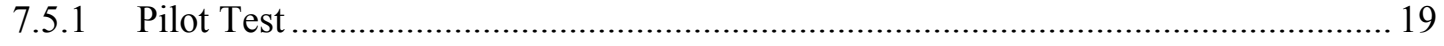

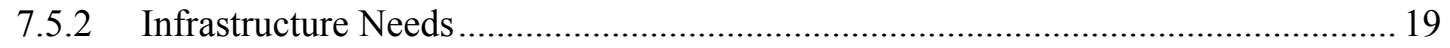

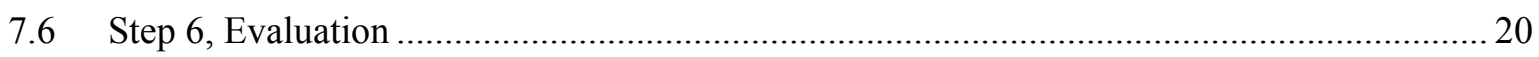

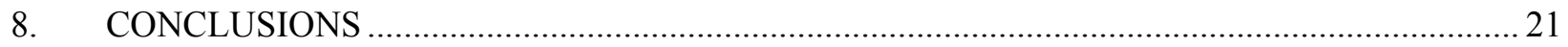

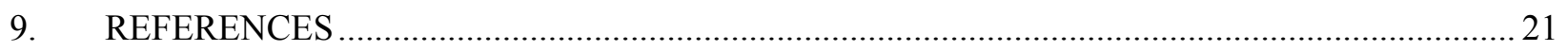

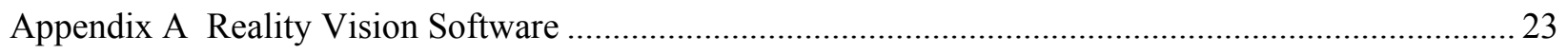

\section{FIGURES}

Figure 1. Applied human performance technology model (adopted from Fundamentals of Performance Technology 2004). 
Figure 2. Process map example: station critical problems to work execution. ........................................ 10

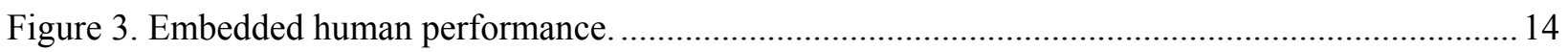

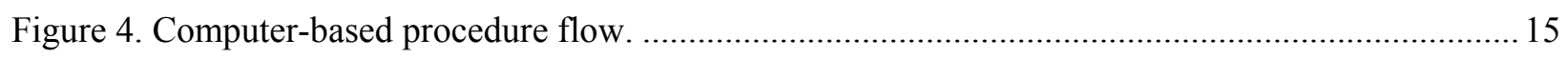

Figure 5. Motion J3500 Tablet PC and Motorola MC-75A................................................................. 15

\section{TABLES}

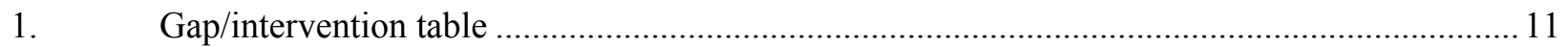

2. Overview of current mobile device capabilities (adopted from cnet.com,

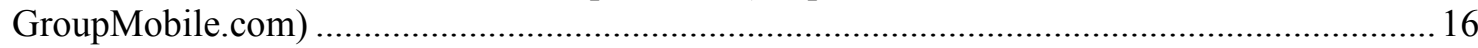

3. Specific uses of mobile technologies in the nuclear industry (EPRI 2009) ............................20

4. Nuclear power industry wireless survey results (EPRI 2009) …...........................................2 20 


\section{ACRONYMS}

CBP computer-based procedure

CNS Catawba Nuclear Station

EPRI Electric Power Research Institute

GPS global positioning system

HFE human factors engineering

HPPP Human Performance Pilot Project

HPT human performance technology

INL Idaho National Laboratory

INPO Institute of Nuclear Power Operations

LWRS Light Water Reactor Sustainability

MCR main control room

NPP nuclear power plant

OCC outage control center

PDA personal digital assistant

PPC plant positioning components

PSC plant status control

RFID radio frequency identification

ROI return on investment

US United States 


\section{Guidance for Deployment of Mobile Technologies for Nuclear Power Plant Field Workers}

\section{INTRODUCTION}

The rate of improvement in human performance and worker efficiency in commercial nuclear power plants (NPPs) has slowed because the current work methods have delivered all the improvement they are capable of and, in some cases, are now adding complexity to the situation, which is a secondary source of problems. This is evidenced by the leveling of the number of events being experienced by the commercial nuclear industry.

Little research has been carried out to assess the impact of mobile devices on collective situational awareness within the commercial nuclear industry. The ubiquitous presence of wireless technology and mobile devices in the form of personal digital assistants, tablets, and smart phones provides an abundance of novel opportunities for advanced work practices, computer-based procedures (CBPs), and information flow between workers and support organizations in real-time. Notable benefits provided by these mobile devices are portability, advanced communication capabilities, information display, and, specifically, the ability to provide field workers with instant access to real-time or near-time NPP data. It also can provide real-time data back to centralized work coordination locations that support command and control activities. Integrating this type of technology into the field offers potential gains in human performance improvement and reliability, reductions in human error and human variability, and embedded validation methodologies. Acknowledgement of the benefits afforded by wireless technology within the industry dates back to the 1990s, with researchers at the Electric Power Research Institute (EPRI) lauding the increased efficiency and projecting "for utilities, the wireless arena will provide to be an indispensable tool for increased worker productivity" (EPRI 1998). Despite their potential impact, portable computers noted at that time had not evolved to provide the critical features necessary for the industry, notably portability, ruggedness, and usability (EPRI 1997).

More than a decade later, there remains a roadblock to successful mobile technology deployment. A number of research pilot projects recently carried out by the Idaho National Laboratory (INL) as part of the Light Water Reactor Sustainability (LWRS) Program provide new information that is intended to support implementation of mobile technologies and impact human performance and process efficiency gains. The LWRS Program, a research and development program sponsored by the Department of Energy, is carried out in collaboration with other industry research and development efforts in order to explore novel technology and engineering solutions for continued operation of U.S. NPPs.

LWRS Program-sponsored research carried out in this effort at the Duke Energy's Catawba Nuclear Power Station in York, South Carolina in early 2012 developed and demonstrated concepts with the potential to enhance human performance, efficiency, and safety through the use of mobile devices. A mix of hardware and software capabilities was developed with the following purposes:

- Reducing the mental workload of field workers that integrated requirements and operator aids into the software

- Increasing overall field work efficiency through remote concurrent verification, rich data availability (e.g., sharing of digital photos, videos, voice, and messaging), and improved audio/visual communications

- Improving plant status control (PSC) by developing and illustrating the impact of electronic schematics that could be updated in real-time

- Incorporating or replacing the need for the current mix of human performance tools by using electronic validation of components through bar code scanning, embedded operating experience, and a simple $\mathrm{CBP}$ that enforces procedural adherence 
- Improving safety by utilizing the innate dynamic characteristics of CBPs by providing context-based information and real-time plant status information that can support decisions in the field by operators and technicians.

A second INL-based LWRS Program pilot project examined the current paper-based procedure method of operation against a proposed CBP method. Researchers maintained that the current paper-based system is static, yet it applied to a dynamic work environment, resulting in excess workload as operators and maintenance personnel search for relevant and applicable information in a mass of paperwork in the form of procedures and maintenance work packages. Therefore, the proposed transition to a more streamlined CBP is proposed to both increase efficiency and reduce human error, which are critical goals in an industry teeming with competition between the current fleet of NPPs and newly built reactors (Oxstrand and Le Blanc 2012).

Additionally, a third LWRS Program pilot project examined deployment of new digital technologies aimed at increasing efficiency and reducing human error during NPP outages. Because outages cost nuclear utilities about one million dollars a day, researchers demonstrated how, through the use of commercially available mobile technology, along with corresponding software applications, increased communication and timely reporting could lead to low cost improvements in outage management techniques that could lead to improved efficiency and reduced outage cost. Conducting safer and, ultimately, more cost-effective outages is important for the long-term operation of existing NPPs (Weatherby 2012).

Data gathered from this research could be implemented into the utility sector with promising results, yet a number of factors, including the following, present formidable roadblocks to this occurring.

- Social paradigms that hinder the adoption of new strategies

- Costs associated with investigating the new data technologies

- Costs associated with implementing new data technologies

- Security risks

- Competing standards

- Battery power dependence.

\section{COST CONSIDERATIONS}

Costs associated with investing in mobile technologies will vary greatly from one NPP to another. The factors that affect the bottom line are beyond the considerations for this paper. However, given the vast variance, some basics should be considered before implementation of mobile technology.

Today many companies of all kinds and sizes are realizing the benefits that mobility technology can bring to their business. The impact can be especially strong for organizations with field-deployed employees, where mobile workers frequently interact with the home base or other field workers. The benefits that can be realized by implementing mobile technology are the keys to justifying the initial cost of the system. Some benefits are easily quantifiable, while others are intangible and difficult to identify. These benefits should be quantified and included in a return-on-investment analysis before development of the final implementation plan.

The NPP can easily identify some tangible savings when the hard cost for printing, administrative cost (i.e., handling, filing, sorting, and change control), and updating of procedures and work orders are considered. Reducing labor for non-value-added paperwork processing can clearly help profitability. Other saving can be recognized and are more difficult to quantify (intangibles) such as those associated with reduction in basic human error and even events that come with paper-based systems (e.g., transposing errors associated with data transfer, using the incorrect or an outdated procedure, 
improper place keeping, and so forth). Error reduction can lend itself to savings in labor cost and process improvement benefits.

Mobile technology and the associated automation help field workers resolve errors in the field, which can further reduce the workload.

At the enterprise level, the most obvious benefit of mobile technology is the reduction of labor needed for data entry and paper-based information processing. Procedure and work order data that are recorded on mobile computers in the field can be easily uploaded to update the appropriate databases. Eliminating these tasks also reduces the opportunity to introduce errors.

When procedure and work order information is recorded on a mobile device, there is little or no lag time for recording it in the enterprise information systems. Reducing information lag times also improves collective situation awareness, which can greatly improve accurate and timely decisions by stakeholders. "Research indicates that wireless technology reduces group decision making time by 30 to 40\%," (GfK NOP World -Technology 2003).

\section{INFRASTRUCTURE}

The commercial nuclear industry will need to invest in the necessary infrastructure to support mobile technologies. Multiple solutions exist to address the various levels of infrastructure needed. Factors to consider for maximizing mobile technology capabilities are existing systems, age of the NPP, remaining life of the NPP, and overall cost. The decision to build-out a wireless system, use docking stations, local area networks, or any combination of these technologies will depend on individual NPP needs.

Data collection is critical once the technology is deployed in the actual work environment to evaluate commercial nuclear industry metrics such as PSC, reduced human error rate, improved procedure use and adherence, mispositioning index, and NPP operations endorsement. Additionally, it is imperative that research be extended to the multitude of technologies available in the form of heads-up (hands-free), mixed reality and virtual reality. The INL Human Factor research organization hopes to gather preliminary data from initial deployment in order to pave the way for valuable contributions to the development and deployment of mobile technology in the commercial nuclear industry.

\section{SECURITY}

Security risk associated with wireless has been a major concern for any number of industries that handle sensitive information; this also is true of the commercial nuclear industry. The commercial nuclear industry has resisted dealing with these security issues and has relied on old technology, a paper-based system, for fieldwork. To break this paradigm, the nuclear industry will need to benchmark other highrisk organizations, including stations which have already begun to deploy this technology to evaluate current practices that guard against the threat posed by outsiders to their systems through the wireless network. A number of solutions exist today as illustrated by the various applications of wireless systems already in use.

A number of advances in technology have been identified that may address the risks perceived in mobile technology implementation. Although signal interference presents challenges, a channel blacklist can prevent congested channels. Another technique to prevent interference is with use of the direct sequence spread spectrum, which spreads the energy of a signal such that it appears as noise by other systems. Additionally, frequency or channel hopping can alleviate the strain on one channel by spreading a signal across an available band (Meynell 2012).

\section{CONDUCT OF OPERATIONS AND MAINTENANCE}

The standards for conduct of operations and conduct of maintenance are well established in the commercial nuclear industry. These standards for operations and maintenance will need to be reassessed to address the use of mobile technology and the change in the approach to operations and maintenance 
that comes from use of mobile devices. The specifics will depend greatly on what and how each NPP adopts mobile technology. Careful consideration should be given before actual field use begins. Each element of the standards should be given careful consideration, because technology use will lead to new possibilities not considered when the standards were written. For example, conflicts will arise when real-time video capabilities are considered for such actions as remote-concurrent verification in lieu of another worker who is present to perform the concurrent verification of a component manipulation.

\section{BACKGROUND}

The LWRS Program has been working with its industry partner Duke Energy to demonstrate new technology to improve human performance in PSC at Catawba Nuclear Station (CNS) in York South Carolina. PSC is the process of maintaining NPP components in the correct position for the given NPP condition. Our approach has been to find new technologies that will maximize the collective situational awareness of the nuclear station staff in order to improve accuracy in positioning NPP components and executing work processes and decision-making. By providing NPP personnel with rich data (i.e., electronic forms, text, video, photos, and voice) in real-time, the NPP groups involved in a work activity can use their combined knowledge and experience to maximize success in PSC. Leveraging recent technological breakthroughs should result in making the right things easy and the wrong things difficult, if not impossible, thus leading to a reduction in human error.

Success in this area will enable nuclear utilities to improve performance during maintenance and operational activities by reducing human error, reducing safety vulnerabilities, and becoming more efficient. These efforts directly support the U.S. Department of Energy's LWRS Program goals to develop technologies and other solutions that can improve reliability, sustain safety, and extend the life of the current reactor fleet.

\subsection{Why Field Workers?}

PSC and human performance continue to be a major challenge for NPP field workers. Workers are challenged by the sheer size of an NPP and the difficult aspect of maintaining a full understanding of the thousands of valves, breakers, and switches that make up the complex systems they operate and monitor on a daily basis.

From researcher discussions with industry leaders, NPP personnel, operators, and field workers, it was clear that the field workers are the work group most likely to benefit from portable devices and wireless technology. By providing this group of workers with rich data sources, work processes and communication with the MCR may be greatly enhanced. Additionally, there is a need to remotely communicate information to and from the field with other decision makers such as supervisors, engineers, and other support organizations. Combined, these capabilities can collectively improve NPP personnel situational awareness, collective situational awareness, and bridge the gap between centralized command and control and field workers.

\subsubsection{Mobile Technologies for Nuclear Power Plant Field Workers}

All NPP work processes follow strict quality and technical standards. The current process provides this information in paper form, which, at times, is difficult to follow and execute without in-depth expert knowledge and training on the process; this is provided by on-the-job and formal training. Use of paper has very limited capabilities to no capability for communicating or transferring information back to stakeholders in real-time. Mobile technologies available today present an endless set of possibilities for information flow, data gathering, and communication, thus almost completely eliminating the need for paper in the field.

A concern about using mobile technology is the ability of the technology to function fully under the environmental conditions that are present in an NPP. Today's field workers need mobility and tools that can withstand the difficult work conditions (e.g., tight areas, climbing ladders, high noise, high 
temperature, and radiation fields) that are often encountered. In addition, to achieve real-time data, a wireless network is needed to support these devices. To date, few NPPs have invested in the necessary wireless backbone infrastructure needed for real-time data streaming. At present, several NPPs have begun to evaluate and or build out wireless in-plant systems. However, docking stations and local area network (hotspots) for near-time data transfer can easily be made available to support mobile device data transfer.

In the world of rapidly changing technology, many mobile devices have the necessary capabilities to address NPP operations and maintenance activities. The number of devices commercially available is growing on a daily basis, introducing additional functionality and capability, while eliminating the need to carry multiple devices to the field. All of these devices have the capability to dramatically improve the collective situational awareness of the NPP. Common to most commercial devices is the ability to bar code scan components; deliver audio, video, and still camera; computing; data storage; and wireless data transmission. These functions have the potential to connect field workers to one another remotely, while providing actual NPP status in the field. In addition, field rugged devices have already been developed for a variety of work environments (e.g., military, medical, or petro-chemical) with challenges similar to those present in NPPs, thus eliminating the need to produce special one-of-a-kind devices specifically designed for the nuclear industry.

The ability to integrate human performance (e.g., job aides) into the technologies is available to move the industry toward the full-scale use of mobile devices. These job aides have been developed to specifically address the current work process and paper-based system fallibilities. A brief description of each tool is given here to understand what is being addressed with the technology:

- Validation and verification - checking work of others or correct component identification

- Self checking - checking your own work prior to and after actions taken

- Clear communication techniques - repeat backs and alpha-numeric communication techniques

- Briefs - in-depth overview of tasks and sharing of lessons learned with workers prior to work execution.

- Procedural compliance - clear expectations as to how procedures are to be performed

- Task observations - supervisor or peer observations of work activities

- $\quad$ Other - additional job aides have been developed that are specific to each NPP.

\section{PROCESS IMPROVEMENT - METHOD}

To improve the current processes associated with PSC and human performance, an innovative approach that creates a step change from the current practices is needed to recognize significant gains in these areas. The focus of this guidance document is on the processes that impact PSC and human performance improvement in the performance of fieldwork.

The LWRS Program research team used a basic approach to performance improvement for the Human Performance Pilot Project (HPPP) concept demonstration - the human performance technology (HPT) model (see Figure 1). The HPT model is a formative approach used by professionals in the International Society of Performance Improvement. This cyclic approach and formative research is well documented and widely adopted by groups responsible for enabling positive change. 


\section{Gap Analysis}

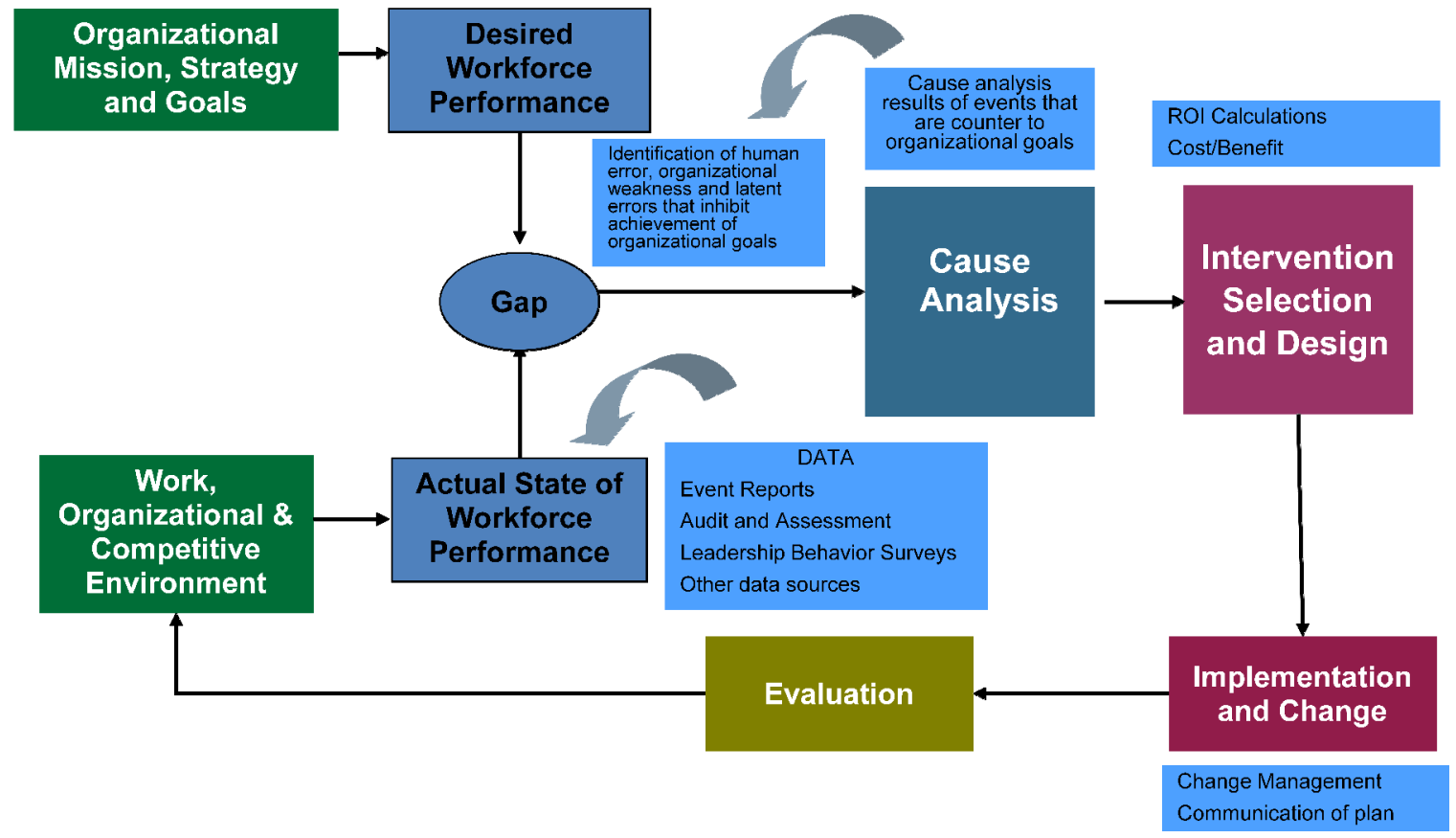

Figure 1. Applied human performance technology model (adopted from Fundamentals of Performance Technology 2004).

Performance technology is the systematic process of linking business goals to strategies with the workforce responsible for achieving the goals (Fundamentals of Performance Technology 2004). Traditional project management approaches seldom take into consideration the complexities of the world of work, the work culture, human behavior, human factors, human performance, cultural norms, and the organizational factors such as strategies, vision, and mission. The HPT model accounts for these factors when prescribing an intervention to improve PSC and human performance metrics.

The HPT model was designed to look at these factors and address them holistically to better understand individual worker behavior and organizational needs. This model takes a systematic approach to unravel this complex world of work and present simple solutions to complex problems that should improve individual and organizational behavior and outcomes. The intent is not to prescribe a single method to solving PSC and human performance issues in commercial NPPs; instead, it is our intent to utilize this one model to illustrate the factors and decision-making process that should be considered prior to employing a vendor, buying wireless systems and mobile devices, and full NPP deployment of mobile devices for field workers.

The basic HPT approach, with some additions, is given in the following list and illustrated in Figure 1:

Step 1: Gap analysis, including process mapping

Step 2: Cause analysis

Step 3: Intervention selection

Step 4: Intervention design (working with vendors and NPP personnel)

Step 5: Intervention implementation

Step 6: Change management and communication plan 
Step 7: Data analysis and reporting.

A detailed description of each step is provided, along with specific examples from the HPPP concept demonstration.

\subsection{Step 1, Gap Analysis}

The purpose of an HPT analysis is to determine the performance gap(s) by comparing the actual (as-is) state of workforce (field workers) performance to the required/desired (to-be) state of workforce performance. The result is a well-defined performance gap (or gaps), validated by supporting data and stated relative to targeted station goals. To determine the current human performance gap(s), a review of NPP events with human performance and mispositioning of NPP components (PSC issues) should be carried out. Interviews with NPP management, human performance leads, and field workers also should be focused on identifying current issues in the "as is" state of human performance and PSC. The INL research team used the basic HPT model to analyze, develop, and demonstrate how mobile technology could improve human performance and PSC.

The LWRS Program pilot project conducted at CNS utilized several methods to collect these data. The team received and analyzed numerous event reports that were either PSC or human performance related. The analysis of these reports clearly indicated that PSC and human performance was and would likely continue to plague the industry by causing events if an innovative approach to these problems was not employed.

The LWRS Program research team also conducted interviews with senior NPP management and human performance leads from CNS. These interviews revealed that the solution was not to pile on additional human performance tools (e.g., job aides). When researchers spoke to these individuals, they were apprehensive to even hear about another human performance job aid, showing the multitude of cards hanging from their security badge lanyards. The situation was at "saturation," with escalating levels of frustration directed at new job aids being stacked upon the job aids currently in place. Rather, field workers expressed a desire to have job aides or tools that would allow them to refocus on the tasks critical to their jobs instead of another job aid added to the list already in use by the workers at the station. One example of this frustration were requirements (procedures) that, at times, called for multiple field workers in the form of second and third checkers to independently validate the work of the first field worker, in essence calling for fallible humans to validate the actions of the first fallible human (Farris and Medema 2012).

Additional gap information was obtained from event reports from the Institute of Nuclear Power Operations (INPO). INPO identified a distinct gap associate with human tools, "Some operators have approached using human performance tools by focusing solely on the technique or practice, without the appropriate focus on the task at hand. Although the human performance tools that have been developed in the industry over the years are very useful and effective, a lack of operator concentration or focus on the task at hand while using these techniques could cause errors and NPP events. The operator who applies solid fundamentals uses the appropriate human performance tools and maintains a high level of concentration and awareness of the task at hand" (INPO 2011).

The following questions and method description is provided to help industry personnel define and validate the performance gap. These questions and method are only recommendations, other methods maybe used to obtain the same information and results, including Six Sigma and other performance analysis methodologies.

These questions can be answered using a variety of simple tools, surveys, questionnaires, interviews, focus groups, and review of existing information from assessments, event reports, and so forth. 
An example of one gap is provided by INPO:

Industry operating experience has shown two extremes regarding the use of procedures and human performance tools. At one extreme, operators followed procedures exactly as written but did not understand the evolution or did not give the task sufficient attention and focus. In these cases, if the plant does not respond properly because of equipment problems or if the procedure is deficient, an event occurs. At the other extreme, many events have occurred in which operators did not follow procedures as written, implemented evolutions with no procedure guidance, or did not properly use human performance techniques that support effective procedure use (INPO Event Report L1-11-3 2011).

\subsubsection{Expected Performance}

The following questions help determine expected performance:

- Who are the field worker groups (e.g., operational field workers, maintenance, chemistry, or radiation control) whose outputs affect the station goal(s)?

- What is the specific role, impact, or influence each field worker group has on achieving the desired station accomplishment(s) (i.e., what are the outputs of the targeted field worker groups)?

- Which specific field worker group(s) should be targeted for this effort (consider where the greatest gains could be realized)?

- Has the optimal performance been defined? Is there a defined standard approach (i.e., conduct of operations) to this performance? If so, describe.

\subsubsection{Actual Performance}

The performance actually occurring can be assessed by asking the following questions:

- What performance currently is happening instead of the required/desired performance (look at event reports, assessments, and station metrics)?

- What is the gap between the current output and the desired output (quantified, if possible, using station metrics)?

- What are field workers (field worker groups) currently doing on the job that results in this performance gap?

- Is the current performance problem/opportunity related to the following:

- Individual field workers (e.g., one or more individuals, but not a whole work group/team/organization)? If so, how?

- A whole field worker group (e.g., operational field workers, maintenance, or chemistry)? If so, how?

- The whole organization? If so, how?

- Does the current performance problem/opportunity involve the following:

- New field workers? If so, how?

- New equipment/technology? If so, how?

- A change in station policy, procedures, or mission? If so, how?

- Consider how to utilize the technology to maximize knowledge capture and transfer to help mitigate for the loss of seasoned workers.

- What internal/external factors (expectations) are influencing this performance? 
- What makes it difficult to accomplish the required/desired result in a successful manner?

- Are any obvious factors affecting the exemplary field workers' performance? If so, what are they?

- What work environment factors (e.g., data, information, feedback, resources, tools, qualified personnel, environment support, consequences, incentives, or rewards) are available to the exemplary field workers?

- How much of the critical factors that affect the exemplary field workers are transferable to the average field workers (i.e., what tools or techniques do they employ to be successful in the same work environment)?

- What criteria are used to determine whether the performance result is a success? Are there any field workers or other comparable sites/facilities/stations that do not have this problem? If so, what do you think is responsible for their success?

- Who (e.g., INPO, EPRI, or Department of Energy) thinks the current performance is a problem? Why? Who disagrees? Why?

- What existing organizational/station initiatives (i.e., "fixes"), if any, currently address the current performance?

- Will these initiatives have an impact on technology deployment? If so, how?

\subsubsection{Performance Gap Description}

Note that a gap must be determined for each field worker group. The following questions may help assess these gaps:

- What is the difference between what "is" being done and what "should be" done? How large is the gap (quantify if possible)?

- How important is the identified gap?

- How often does the gap occur (quantify if possible)?

- What does the gap cost the organization in lost performance (quantify if possible using current station metrics if possible)?

Once the true performance gap has been identified, is it still linked to the performance issue (i.e., wrong component operation, wrong train selection (redundant systems), wrong unit operations, NPP transients, and NPP trips) that was initially described, or is it related to an issue that was not initially targeted? If different, the project scope may need to be revised. For each field worker group, write a gap statement that reflects the discrepancy between what "should be" happening and what "is" happening.

\subsubsection{Process Mapping}

It is highly recommended that detailed process mapping be conducted in order to better understand the current work processes at the station and identify areas that could be improved by using the solutions that are analyzed. Form a diverse team that can be employed to participate and develop the process maps, with a focus on standard work practices for both operations and maintenance activities. These maps can pinpoint process improvement points with the information gained from the gap analysis to fully illustrate how and where the process can be improved through mobile technology deployment. As an example, the focus on past NPP events and corrective actions will further the understanding of the current "as is" state and how the current processes contributed to the identified issues. A simple process map used for work at CNS is provided in Figure 2. 
Figure 2. Process map example: station critical problems to work execution.

The HPPP team developed process maps that help visualize the current processes to be addressed. The focus of these process maps was on identification of standard work execution during operations and maintenance activities. The team, which consisted of CNS and INL personnel, worked to integrate mobile technology capabilities into the current process maps to address known issues. This process helped to illustrate how new and innovative methods, combined with mobile technology, could greatly enhance fieldwork. This process and subsequent data were extremely useful in helping define the current state and challenges in PSC and human performance and shape the "to be" state that is possible today.

Additionally, the process maps were used as the basis for scenario development and concept demonstration at CNS.

The greatest advantage of process mapping is that it provides a visual tool to illustrate current and future processes. In process mapping, basic flowchart symbols represent the flow of information or work process elements. The process map illustrates how a process occurs from beginning to end or how a given process links to another process. Typically, symbols and written details are included on process maps, such as which worker performs a step and the type of work performed in that step. Field workers, supervisors, and managers can use a process map to better understand their jobs or tasks and illustrate to others these process functions and tasks.

The importance of using a diverse team of experts and end users cannot be overstated. One of the greatest advantages to using a diverse team to develop process maps is the buy-in by all involved in creation. The process lends itself to sharing of ideas, roles, responsibilities, and knowledge by all involved, which leads to ownership of issues and more importantly intervention ideas.

Using a facilitator with human performance improvement or six-sigma skills training will lead to better process maps and more comprehensive interventions that address the issues identified by the process maps, gap analysis, and cause analysis (described in the following sections). 


\subsection{Step 2, Cause Analysis}

Cause analysis is the most important step in the human performance improvement process because it drives an organization or management away from an immediate solution (intervention) following gap analysis. The purpose of cause analysis is to analyze what factors are contributing or directly causing the performance gaps identified in gap analysis and process mapping. Correct analysis will lend itself to the correct intervention selection and design to close the identified performance gap(s). The current cause analysis and event investigations tools typically deployed by NPPs will suffice in the cause analysis process. Typical outputs of a cause analysis include the following:

- A comprehensive list of probable causes backed up by facts and supporting data

- Hypotheses for each plausible root cause (with supporting data)

- A list of potential interventions based on gap and cause analysis.

It is more important to follow a systematic approach to determine causes that are already in use at the station, than it is to recommend a specific method.

\subsection{Step 3, Intervention Selection}

Selection of the correct intervention is critical to the success of any project. Too often, organizations jump to solutions without the appropriate level of analysis described in the gap and cause analysis. The HPPP team approached the intervention selection only after analyzing all data and working closely with NPP personnel to validate the approach and intervention selection. The mobile technology and software tools were only selected based on these analyses to close the gaps and address the causes of those gaps. Table 1 provides examples of identified gaps and the corresponding interventions that were identified for the HPPP.

Table 1 represents possible solutions/interventions to improve human performance and PSC (this list is representative of the possibilities, other possibilities likely exist). Note it is recognized that all of these elements can lead to improved productivity; however, each potential solution was placed in the primary improvement area. Although all of these solutions were not incorporated into the research, the possibility exists to do so given today's technology. Thirty-two participants provided input to the team that lead to these interventions/solutions.

Table 1. Gap/intervention table.

\section{Wrong Component}

- Reduction in wrong component/train selection can be eliminated through bar scanning the component bar code.

\section{Human Performance}

- The CBP can alert the field worker when a suspicious value (i.e., torque readings) have been recorded.

- Field operators performing actions resulting in system alarms can view the alarm on the mobile device and take immediate mitigating actions without unnecessary delay, which can lead to improved system analysis and response.

- When non-consequential error points occur in the field during the process of executing the task, these errors can be identified through automatic data collection (i.e., bar code scanning the wrong component). Data analysis can reveal the causes and allowing for process improvement.

- CBP usage can enable an updated procedure to be uploaded when a mobile device is put into service.

- Transposing errors by field workers can be reduced by using blue-tooth connected calibrated tools (e.g., remote monitors, electronic meters, or torque wrenches) that correctly transmit the data to the procedure or work order. 


\section{Productivity/Efficiency}

- Providing various stakeholder with real-time or near-time information (such as task completion, task progress, and task or subtask time estimates) can enable better work planning in real time leading to improved work planning and coordination (i.e., CBP usage can alert individuals or shops [such as Quality Assurance] when they will be needed at the work site).

- Mobile technology capabilities (audio/video) can provide for real-time problem identification, remote collaboration, and decision making, leading to improved productivity and emergent issue resolution.

- Remote system operations can be realized; field workers can perform tasks directly without needing to verbally request permission from the MCR.

\section{Mispositioning of Components}

- Reduction in mispositioning of components through bar code use.

\section{Procedure Use and Adherence}

- CBPs can eliminate individual decision making in the field and will enforce the use of the procedure as written.

\section{Operating Experience}

- The capture of rich data in the form of audio, video, or annotated digital photos can support future usage of operating experience in CBPs, job briefs, or meetings.

- Embedded operating experience in the form of rich data can improve the operating experience message, leading to improved performance.

\section{Communication}

- Improved communication with the supervisor and other stakeholders can be realized when rich data in real-time or near-time is transmitted to and/or from the field.

- Task status can be updated on a regular basis in the Outage Control Center (OCC); stakeholders can receive updates without disrupting work activities.

\section{PSC}

- Improved PSC can be improved when key process information is updated in real-time or near-time, providing the MCR and field workers with a detailed view of the actual state of the system being manipulated.

\section{Situational Awareness}

- The use of CBP and mobile technology can provide field workers the capability to transmit rich data from the field to OCC or MCR, greatly improving the collective situational awareness of facility personnel.

\section{Decision Making}

- Improved decision-making can be realized when situational awareness (actual plant status) is available to field workers, OCC, and the MCR.

\section{Focus on Task}

- The field workers' mental workload can be lowered when the worker has access to the necessary information, including requirements, that is seamlessly integrated into the CBP to perform the task at hand (task focus versus process focus).

\section{ALARA (As Low As Reasonably Achievable)}

- Improved communication capabilities using mobile technologies to transmit rich data from the field to stakeholders could enable remote decision-making and minimizing unnecessary radiation exposure to decision makers who might otherwise need to visually see the issue (ALARA could be greatly improved). 
Nuclear Safety

- Use of CBPs can prevent individual work around without supervisor acknowledgement and consent (e.g., skipping a step or NA a step).

- Use of CBPs that encompass tight controls that drive procedural and process adherence to the requirements can realize improved risk management.

- Building NPP mode sensitivity into the CBP can be used to flag or restrict operations based on the current operational mode and could prevent unwanted actions that place the NPP in an undesired condition.

- Error points and other data that is collected and time stamped can be used to improve accident/incident reconstruction post event.

It is a common practice for software and hardware vendors to push their products onto customers (i.e., they prescribe a solution without analyzing the situation). Following the prescribed process provided in this document will leverage the NPP station to create pull and establish requirements for both hardware and software based on the needs of the organization. When the method described above is utilized, the correct intervention becomes obvious; however, intervention selection (i.e., hardware and software) selection comes down to two key elements: return on investment and workforce acceptance of the intervention. Based on the gap and cause analysis, there will likely be a number of possible approaches to closing each performance gap, including, but not limited to, the following:

- Redesigning measures and metrics related to PSC, human performance, and mispositioning index

- Providing better technological tools for field workers

- Streamlining processes due to better information flow

- Leveraging technology to create better feedback mechanisms

- Managing resistance to change by improving sponsorship and change-agent skills

- Delivering just-in-time information to field workers prior to task execution

- Using component verification tools (e.g., bar codes, radio frequency identification, character recognition, or other technological solutions to component verification) to prevent wrong component, wrong train, and wrong NPP errors

- Using technology verification tools to update electronic NPP diagrams and thereby improve PSC

- Leveraging real-time data (such a video and audio data) to improve communication, data collection, and decision making

- Integrating human performance job aides into the technology to reduce human error

- Eliminating procedure deviations by using CBPs

- Using just-in-time or as needed operating experience information prior to task execution to transfer knowledge of past events and improve performance

- Eliminating the need for second and third checkers by leveraging remote concurrent verification using streaming video.

\subsubsection{Mobile Technology Software and Hardware}

7.3.1.1 Interface considerations. One goal of the project was to stimulate a discussion related to the use of mobile technologies by field workers and the broad range of potential benefits that would come from their use. In this section, three interface considerations that the research team evaluated prior to software development and hardware integration are discussed. HFE considerations (such as ergonomics, portability of the digital devices, ambient lighting, ambient environmental conditions [e.g., radiation, dust, 
or temperature extremes], and interference with personal protective equipment [gloves or safety glasses]), also were considered.

The following lists specific interventions developed by the research team. The first intervention consideration was human performance with elements considered which could close the identified gaps between PSC and human performance:

- Human performance operator aide use (human performance tools): Software was developed that integrated human performance job aides and that was a transparent application on a mobile device.

This allowed the worker to focus on the task and not the current job aides (i.e., three-part communication or repeat backs). Figure 3 shows how some elements of human performance were addressed with the software developed by the LWRS Program research team at INL.

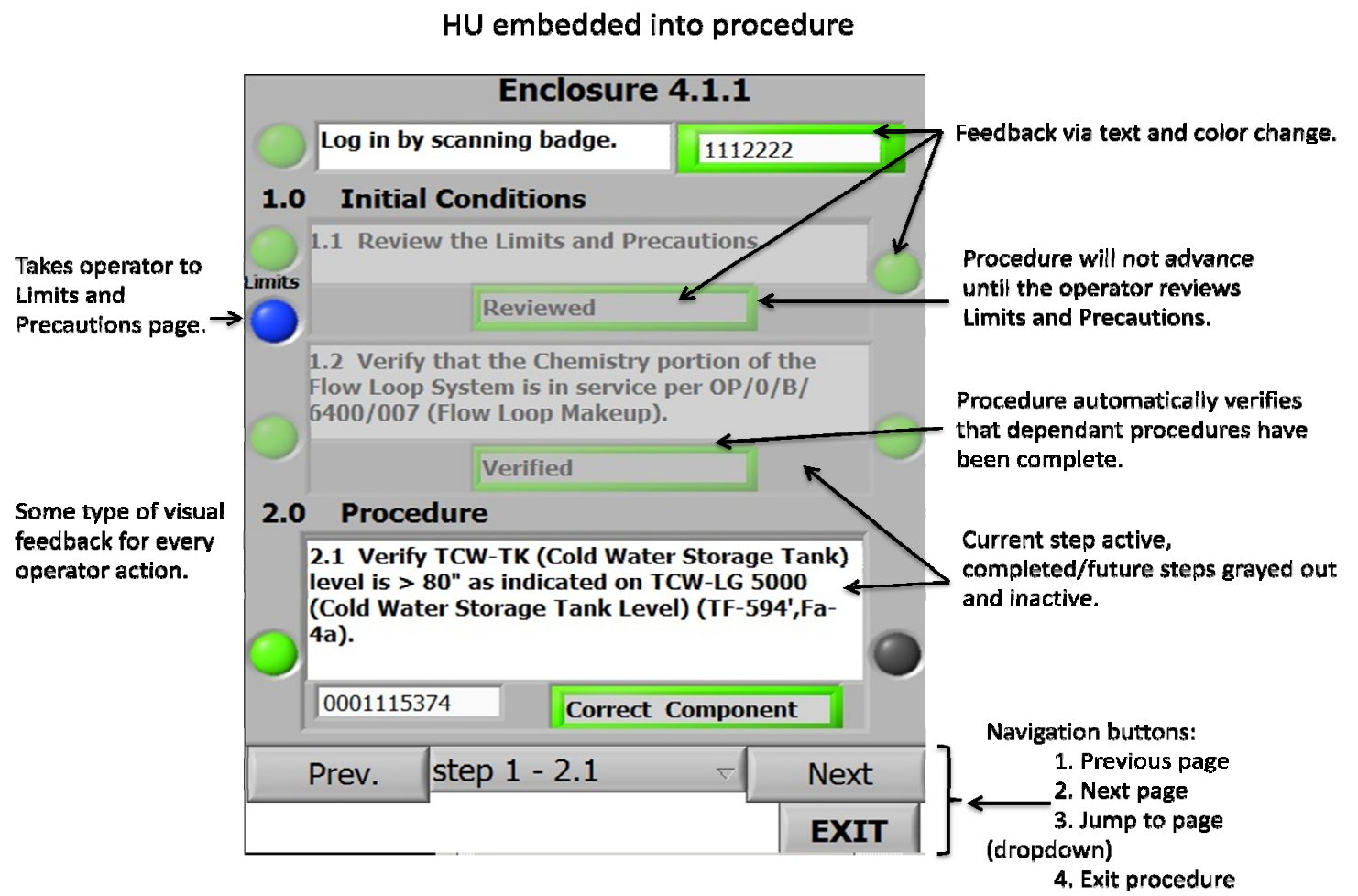

Figure 3. Embedded human performance.

- Error reduction: The software and hardware used current bar codes on NPP components to support the field worker in the reduction errors that come from wrong component/train selection. Simply put, this enabled correct task execution by making the right actions easy and the wrong actions by the field worker difficult, if not impossible.

- Compliance: By using a CBP on the mobile device, the field worker could not deviate from the instructions (e.g., performing steps out of order or as written). The software developed for CBP application eliminated individual decision making in the field and enforced the use of the procedure as written (procedure use and adherence). This supports risk analysis and field execution as prescribed by procedure developers. Figure 4 shows how procedure flow was handled by the software. 


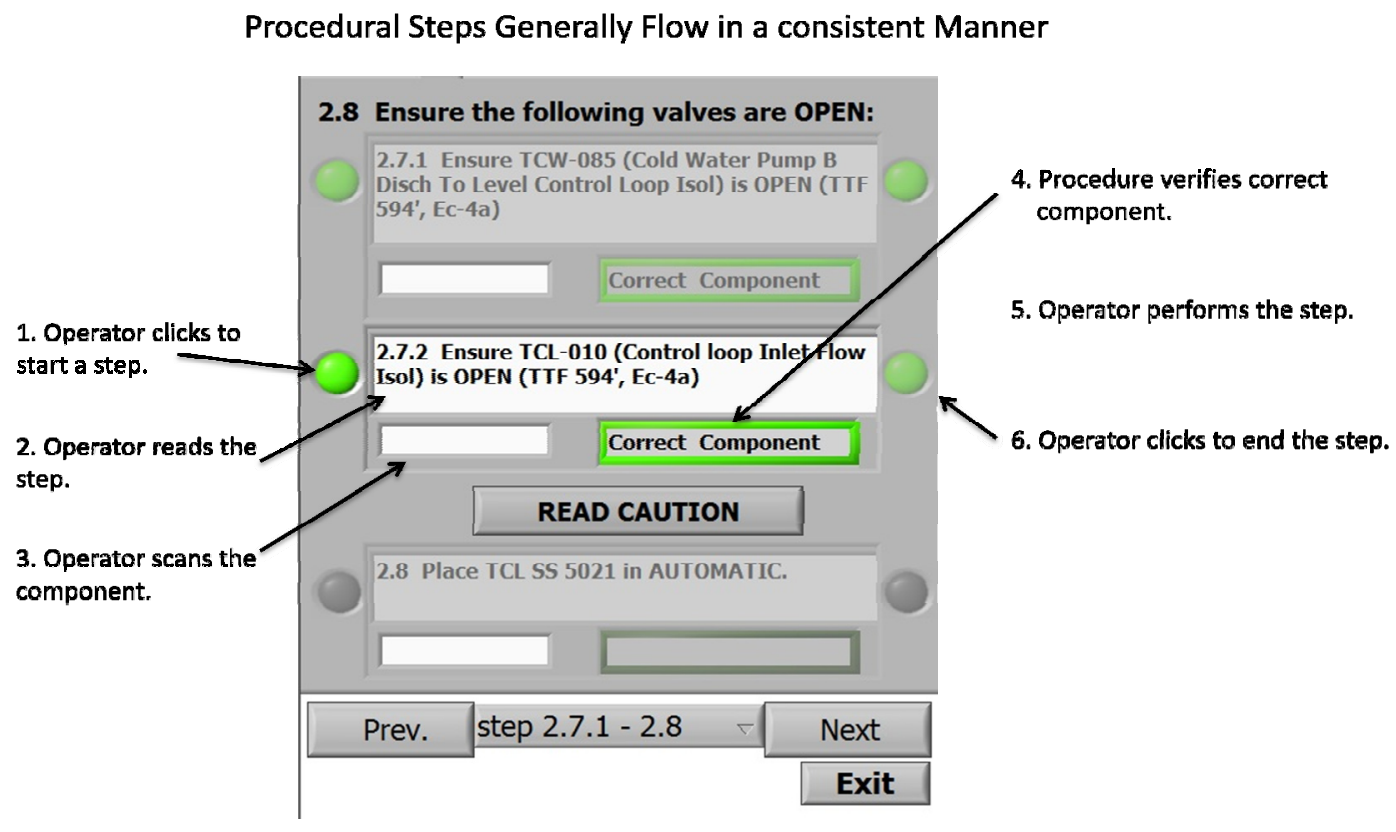

Figure 4. Computer-based procedure flow.

- PSC: Task status can be updated on a regular basis in the information and communication center and stakeholders can receive updates without disrupting work activities.

- Graphics: The ability to display videos, pictures, diagrams, schematics, or drawings with details and efficiency.

- Information management and communication: Software was selected that would enable field workers to send or receive information to and from the field in the form of rich data capture and transfer using audio, video, and annotated digital photos. RealityVision software by RealityMobile was selected to address this need (Appendix A). The capability also allowed instant access to real-time data, as well as the ability to communicate more directly and effectively with the decision makers. This information transfer illustrated the possibility for more accurate information flow and parallel decision making versus the current method of series decision-making that is much more time consuming. This can be especially important for time-critical decisions.

The second intervention consideration was hardware selection. Early in the research process, it was decided that commercial off-the-shelf technology would be used whenever possible, along with proof of concepts, rather than development of a field deployable product (software or hardware). One tablet device was selected and one small mobile device (Figure 5). This was based on the selection criteria as follows:
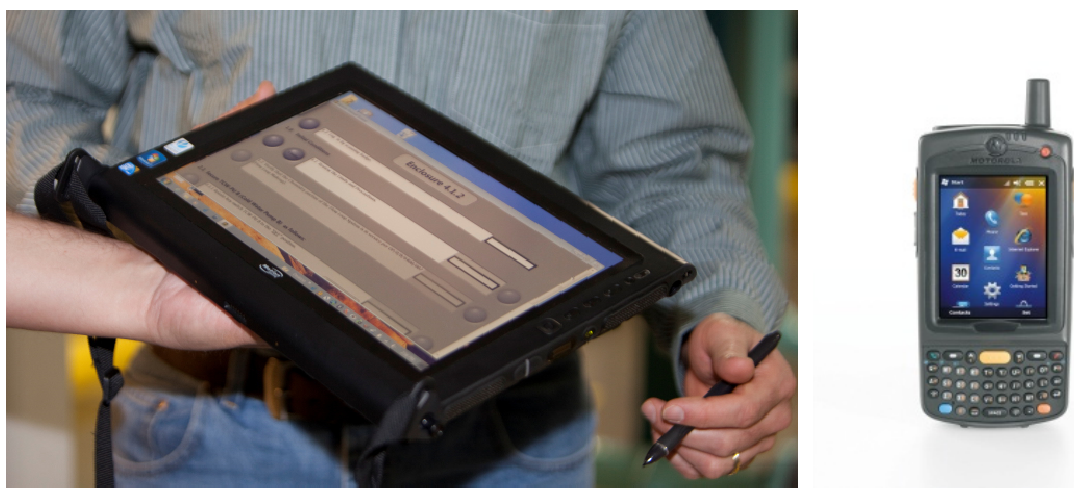

Figure 5. Motion J3500 Tablet PC and Motorola MC-75A. 
- Usability: this was based on the field workers' information needs and other HFE considerations (such as ergonomics, ambient lighting, interference with personal protective equipment [e.g., gloves and safety glasses]) also were considered.

- Cost: the cost of hardware can vary greatly; consideration was given based on input from CNS personnel.

- Adaptability: the hardware devices were selected on their ability to integrate other wireless forms (e.g. blue-toothed devices to ring bar code scanner).

- Portability: the device should support field workers in an NPP work environment.

- Functionality: see Table 2 for a list of possible devices and their associated features/benefits.

- Size: the relative size of the mobile device was considered for portability (i.e. climbing ladders), including the user interface that supported gloves that are commonly worn by field workers.

- Display screen: the display size was selected to minimize the "key-hole" effect, although smaller devices were considered because of portability (there is always a trade-off in this area that comes down to personal preference).

- Ruggedness: devices were selected that would withstand the NPP work environment (e.g., radiation, dust, temperature extremes, and the potential for elevated drops).

Table 2. Overview of current mobile device capabilities (cnet.com, GroupMobile.com).

\begin{tabular}{|l|l|}
\hline \multicolumn{1}{|c|}{ Device } & \multicolumn{1}{c|}{ Features and Benefits } \\
\hline $\begin{array}{l}\text { Personal Digital Assistant } \\
\text { Smart Phone }\end{array}$ & $\begin{array}{l}\text { Functions both as a cell phone and computer } \\
\text { Provides email functions } \\
\text { Transmits streaming audio, images, and video information, as well as } \\
\text { GPS components. }\end{array}$ \\
\hline Tablets & $\begin{array}{l}\text { Instant communication } \\
\text { Email access } \\
\text { Video and photo capabilities }\end{array}$ \\
\hline Laptops & $\begin{array}{l}\text { Portability } \\
\text { Lightweight laptop option }\end{array}$ \\
\hline $\begin{array}{l}\text { Rugged Handheld } \\
\text { Computers }\end{array}$ & $\begin{array}{l}\text { Portability } \\
\text { Intended to be one-hand portable } \\
\text { Slightly larger than a PDA } \\
\text { Provides increased protection - sealed against elements and also protected } \\
\text { from vibration and drops } \\
\text { Daylight-viewable screens } \\
\text { Lack a hard disk drive, relying on onboard memory or flash drive } \\
\text { memory } \\
\text { Run scaled down operating system such as Pocket PC or Windows } \\
\text { Mobile rather than standard Windows operating systems }\end{array}$ \\
\hline $\begin{array}{l}\text { Head-Mounted Displays } \\
\text { (Golden-i) }\end{array}$ & $\begin{array}{l}\text { Provides status information } \\
\text { Transmits real-time video } \\
\text { Provides interior map } \\
\text { Increases situational awareness (Arico 2012) }\end{array}$ \\
\hline Wireless Scanner & $\begin{array}{l}\text { Handheld scanners } \\
\text { Can identify an item, take inventory of a group of items, and record when }\end{array}$ \\
\hline
\end{tabular}




\begin{tabular}{|l|l|}
\hline \multicolumn{1}{|c|}{ Device } & \multicolumn{1}{c|}{ Features and Benefits } \\
\hline RFID & a part is used or replaced - all from a barcode \\
\hline $\begin{array}{l}\text { Radio frequency identification technology - rely on radio waves to } \\
\text { provide real-time, wireless transmission of data without a scanner, and } \\
\text { can be used for inventory of assets }\end{array}$ \\
\hline $\begin{array}{l}\text { Handheld Scanner and } \\
\text { Software (Matterport) }\end{array}$ & $\begin{array}{l}\text { Captures physical environments into three-dimensional images, can scan } \\
\text { any part of a room in any order (much like a jigsaw puzzle); sensors will } \\
\text { be smaller and more integrated in next 2 to 5 years }\end{array}$ \\
\hline
\end{tabular}

The third intervention element was software development, and the following HFE elements were considered:

- Display appearance: the applications developed by the research team mitigated for the "key-hole" effect and reduced excessive navigation.

- Training: software design was based on simple and intuitive principles that would reduce the learning curve for field workers and ease the transition from the current paper-based process to the CBP.

- Lesson learned: the HPPP used a pilot project prior to in-depth demonstration and utilized the lessons learned from the pilot project to improve the intervention.

- Information details: considerations were given for the detail level of the contextual information being presented both in the field and in the information control center.

- Feedback or acknowledgment: the software was developed such that every operator action was followed by some type of feedback or acknowledgment

- Human performance principles and practices: consideration of current human performance principles and practices

- CBP process flow: the software was designed to guide the operator through the procedure (e.g., choosing the appropriate next step for "if/then" statements or cautions and notes must be read prior to associated steps).

- Action monitoring: wherever possible, the software would monitor the operators actions (e.g., check data entry values for out-of-range values or provide alerts in the event a wrong component bar code was scanned).

\subsection{Step 4, Intervention Design}

Pay particular attention to human and technology interactions for the given tasks, various databases, and between the flow of information and the system components during the design phase of the process. As an example, converting current written procedures to a pdf format and putting them on a mobile device does not take into consideration all the human performance and human factor considerations needed to improve operations or maintenance activities. The implementation team also should take a thorough look at the station architecture and databases to help redefine functions and tasks as necessary to meet process requirements to accomplish selected task on mobile devices. The team should determine whether or not the specified levels of activity (e.g., physical or mental) of both humans and NPP systems can be met with the technology to be deployed in the field and in control and information centers in the NPP. Once the functional architecture meets the station's mission needs and system requirements, operator interfaces may be specified and designed based on standard HFE guidelines. 


\subsubsection{Design - Human System Interfaces}

Apply basic HFE when designing the interfaces between humans and both hardware and software. Development of technology capabilities that enhance team performance through improved communications and collaboration should be part of the solution set. The importance of good communication between workers, supervisors, and crews cannot be over emphasized. The design phase should have particular focus on communication capabilities, including voice, streaming video, component status, NPP parameters, and any other relevant information that improves the collective situational awareness of NPP personnel to improve decision making at all levels. The level of importance can be seen in an INPO event report:

Communication is an important aspect of teamwork. Crewmembers communicate clearly and regularly to share important information and clarify priorities. Good communications ensure crew alignment and allow an individual crewmember to confirm his or her understanding of plant conditions and decision-making (INPO 2011).

\subsection{Step 5, Intervention Implementation}

A number of processes and organizations may contribute to building the integrated technology solution components. During this phase, select members of the implementation team should stay engaged to conduct initial assessments and provide important feedback to the full team as interventions are designed. Research and development should be conducted, when necessary, on the basis that no solutions exist in the marketplace when specialized interventions are required.

Now that the magnitude of the remaining effort is known, the implementation plan will likely need to be revised or a new implementation plan should be prepared. The expected outputs, milestones, and deliverables of the intervention planning are as follows:

- Develop an implementation strategy

- Revise/develop a change management plan

- Obtain stakeholder approval.

The general process includes the following milestones and deliverables:

- Develop implementation strategy

- Prepare a design document that includes intervention requirements, components, and specifications.

- Prepare an action plan that lists the major tasks included for each intervention, the resources required to implement each intervention (including possible partner organizations), and a plan for incorporating stakeholder support.

- Prepare a statement of work (as necessary) for each intervention component.

- Prepare a pilot test plan (when applicable), including test and brief/report for approval.

- Prepare a measurement and evaluation plan for pilot test (when conducting a pilot).

- Determine who will manage the project and what the timing and budget requirements are.

- Determine how solutions will be integrated with other processes and systems.

- Revise/develop a change management and communication plan

- Secure stakeholder approval. 


\subsubsection{Pilot Test}

A pilot test is highly recommended prior to full-scale deployment in the NPP and may be appropriate before approving full development. The pilot test should provide adequate feedback to the development team to either pull the effort back for further design and revision or push the effort forward after proving it successful.

This phase of the process also requires working with station stakeholders to coordinate the introduction of mobile devices in the real NPP work environment, applying good change management processes. Specific deliverables for this phase include pilot testing plans, pilot testing reports (including performance data), and a record of configuration changes. The suite of solutions should include measurement and evaluation of the pilot test. Throughout pilot testing, a well-defined set of metrics should be established and in place that will continually be collected and analyzed to predict technology effectiveness and return on investment. As with all pilot testing, the intent is to provide a less expensive, less intrusive, small-scale field test of the chosen technology. The pilot results are crucial for making a decision about whether to fully implement the solution.

As seen previously in Table 2, the most common mobile devices are capable of supporting process improvement as it relates to PSC and human performance. In also can be seen in Table 2 that one tool will not address all of the needs of a particular process. Consideration will need to be given to select the correct tool (i.e., mobile device) in order to best match the tool with the worker, given the task to be accomplished, to ensure maximum efficiency gains and overall process improvement. The rapid speed of change in the mobile technology industry will continue to provide more possibilities beyond the current list of capabilities listed.

Besides technology selection, additional consideration should be given to the role of the human factors professional and human performance leads at the station. Although these professionals are not necessarily responsible for implementing the selected intervention, it is important to have them engaged with those who are responsible for it. The following four change management elements of this phase should be watched closely:

- Intervention/solution - during implementation, watch how people within the organization respond to the changes to the work processes.

- Organization(s) - an intervention will only succeed if the organization is ready for it.

- Station leadership - how they represent the intervention publically; organizational leadership can make or break an intervention.

- Individuals affected by the intervention - how well are they adapt to the change.

\subsubsection{Infrastructure Needs}

A final consideration is the station's infrastructure needs to support mobile technology solutions, because the need to compete with other power-producing industries and even the new fleet of nuclear reactors' need for the commercial nuclear industry to invest in the necessary infrastructure to support mobile technologies will grow. Drivers will come from factors such as greater safety, greater efficiency, and productivity in NPP operations and maintenance and a reduction in unplanned events caused by human error. The solutions will come from leveraging the capabilities of modern technology to improve work processes by allowing improved data collection and transfer, process tracking, work flow, communication, coordination, and emergent issue resolution. As can be seen Tables 3 and 4, some stations have begun the migration toward wireless systems infrastructure. 
Table 3. Specific uses of mobile technologies in the nuclear industry (EPRI 2009).

\begin{tabular}{|c|c|c|c|c|c|c|c|}
\hline $\begin{array}{l}\text { NPP Type and } \\
\text { Location }\end{array}$ & $\begin{array}{c}\text { Voice } \\
\text { Communication } \\
\end{array}$ & $\begin{array}{c}\text { Laptop/ } \\
\text { PDA }\end{array}$ & $\begin{array}{l}\text { Equipment } \\
\text { Monitoring } \\
\end{array}$ & $\begin{array}{c}\text { Camera } \\
\text { Monitoring } \\
\end{array}$ & $\begin{array}{c}\text { Wireless } \\
\text { Dosimetry }\end{array}$ & $\begin{array}{c}\text { Heavy } \\
\text { Equipment } \\
\text { Operation } \\
\end{array}$ & $\begin{array}{c}\text { Process } \\
\text { Monitoring } \\
\end{array}$ \\
\hline $\begin{array}{l}\text { Arkansas Nuclear } \\
\text { One } \\
\text { Babcock \& Wilcox } \\
\text { PWR } \\
\text { Russelville, Arkansas }\end{array}$ & $\sqrt{ }$ & $\sqrt{ }$ & & $\sqrt{ }$ & $\sqrt{ }$ & & \\
\hline $\begin{array}{l}\text { Comanche Peak } \\
\text { Westinghouse PWR } \\
\text { Glen Rose, Texas }\end{array}$ & $\sqrt{ }$ & $\sqrt{ }$ & $\sqrt{ }$ & $\sqrt{ }$ & & & \\
\hline $\begin{array}{l}\text { Diablo Canyon } \\
\text { Westinghouse PWR } \\
\text { San Luis Obispo, } \\
\text { California }\end{array}$ & $\sqrt{ }$ & $\sqrt{ }$ & & & $\sqrt{ }$ & & \\
\hline $\begin{array}{l}\text { Farley } \\
\text { Westinghouse PWR } \\
\text { Dothan, Alabama }\end{array}$ & $\sqrt{ }$ & $\sqrt{ }$ & & $\sqrt{ }$ & $\sqrt{ }$ & & \\
\hline $\begin{array}{l}\text { San Onofre } \\
\text { Combustion } \\
\text { Engineering } \\
\text { PWR, San Clemente, } \\
\text { California }\end{array}$ & & & $\sqrt{ }$ & & & & $\sqrt{ }$ \\
\hline $\begin{array}{l}\text { South Texas Project } \\
\text { Westinghouse PWR } \\
\text { Bay City, Texas }\end{array}$ & \multicolumn{6}{|c|}{ In development } & \\
\hline
\end{tabular}

Table 4. Nuclear power industry wireless survey results (EPRI 2009).

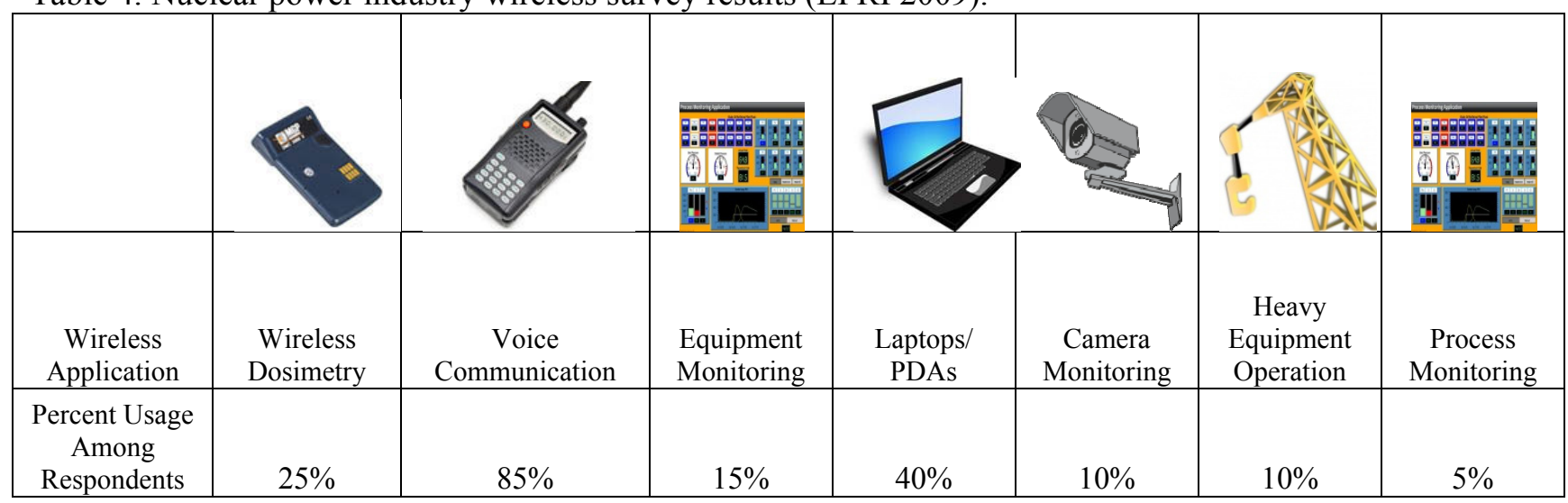

\subsection{Step 6, Evaluation}

An evaluation should be done after each phase of the process of the HPT model. It is recommended that formative evaluation be used during the performance analysis, cause analysis, intervention selection and design, and implementation phases. Well-defined metrics of success should be identified for each phase and quantified if possible. The implementation team should focus on the field workers and organizations that are impacted by the change and how they conform to the desired behaviors and outcomes. Lastly, the implementation team should evaluate the overall improvement of the desired 
outcomes (such as human error, mispositioning of components, productivity, efficiency gains, and safety), as well as determining return on investment for the selected intervention.

As a final note, because evaluation is a complex topic and an even more complex undertaking, the implementation team invariably will need to call upon measurement and evaluation expertise.

\section{CONCLUSIONS}

Improving PSC and human performance with mobile technology has been demonstrated as a way to improve productivity, efficiency, safety, and the collective situational awareness of NPP field workers in the current U.S. nuclear fleet. Although, few NPPs in the United States have the necessary wireless systems to support mobile technology for real-time data transfer, there are other solutions that will still improve information flow should this solution be deployed. The LWRS Program researchers have established that there is substantial interest in the U.S. nuclear power industry to invest in mobile technology solutions to improve the NPP fieldwork processes in the near future. In order for wide-scale deployment of mobile technology in the existing NPPs to occur, the industry needs a set of standards or requirements for mobile technology and to demonstrate how to deploy such solutions. The LWRS Program researchers have taken the first step in demonstrating how mobile technology solutions can improve PSC and human performance for NPP fieldwork activities. The researchers also have identified how potential solutions (such as remote concurrent verification, PSC data transfer, and CBPs), when deployed on mobile technology devices, can improve the collective situational awareness of NPP personnel to improve decision making. The researchers have developed guidance for NPPs to take their first step toward improving fieldwork activities using human centric solutions on mobile devices. Together, this guidance and support from LWRS Program researchers can provide support for the first utility to take its first step toward process improvement in PSC and human performance using mobile devices.

\section{REFERENCES}

Arico, J., (2012). Wear a Full Computer on Your Head. Retrieved June 25, 2012 from http://www.mobiledia.com.

General CNET Product Reviews. Retrieved June 25, 2012 from http://www.cnet.com.

EPRI 01019186, 2009, Implementation Guideline for Wireless Networks and Wireless Equipment Condition Monitoring, Final Report, Electric Power Research Institute.

EPRI TR-110125, 1998, Assessments of Emerging Technologies for Wireless Communication, Final Report, Electric Power Research Institute.

EPRI TR-107790, 1997, Evaluation of Pen-Based and Hands-Free Computers for the Electric Utility Industry, Final Report, Electric Power Research Institute.

Farris, R. K. and H. D, Medema, 2012, Advanced Instrumentation, Information and Control (II \& C) Research and Development Facility Buildout and Project Execution of LWRS II \& C Pilot Project 3, INL/MIS-12-25139, Idaho National Laboratory.

GfK NOP World -Technology Study 2003. Retrieved from http://www.gfk.com, September 1, 2012.

INPO L1-11-3, 2011, Event Report.

Meynell, J. Plant-wide wireless: Risk or Reward? Retrieved June 26, 2012 from PACE Magazine online, http://www.Pacetoday.com.au/news/plant-wide-wireless-risk-or-reward. 
Oxstrand, J. H. and K. Le Blanc, 2012, Computer-based Procedures for Field Workers in Nuclear Power Plants: Development of a Model of Procedure Usage and Identification of Requirements, INL/EXT-12-25671, Idaho National Laboratory.

Roth, E. and J. O'Hara, 2002, Integrating digital and conventional human system interface technology: Lessons learned from a control room modernization program, NUREG/CR-6749, Washington, D.C.: U.S. Nuclear Regulatory Commission.

Van Tien, D.M.,Mosely, J.L. and J.C. Dessinger. (2004).Fundamentals of Performance Technology: A Guide to Improving People, Process, and Performance. Intl Society for Performance.

Weatherby, G. D., 2012, Resolving Emergent Issues During Reactor Outages, INL/MIS-12-26413, Idaho National Laboratory.

Your Guide to Rugged Mobile Computers. Retrieved June 25, 2012 from http://www.GroupMobile.com. 


\section{Appendix A}

\section{Reality Vision Software}

\section{How it Works:}

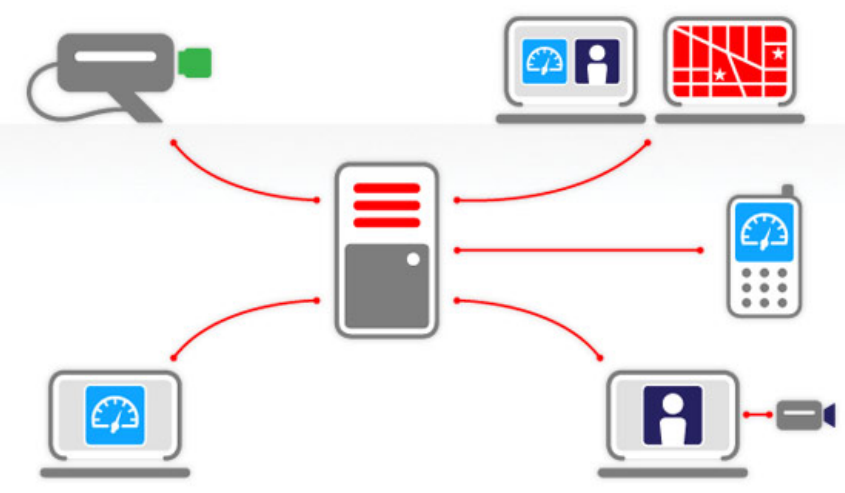

1. RealityVision server software( $\equiv$ ):

a. Installed inside the firewall

b. Creates private communication

c. All data streaming secured with:

1) User authentication

2) High-level SSL encryption.

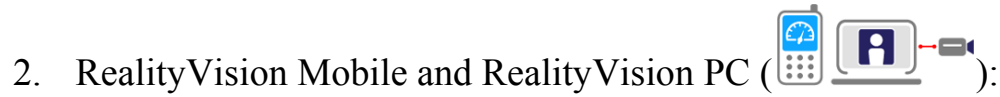

a. Runs on any wireless device (e.g., Smart Phones or laptops with cameras)

b. Authorized users can do the following:

1) Stream video feeds from any camera source

2) Automatically report GPS coordinates

3) Add a descriptive text comment at the end of each video stream

4) Remotely control network camera movements

5) Initiate a silent alert for assistance.

3. Reality management console (

a. Allows to visualize, control, and monitor all the data

b. Tracks location of all system users and video sources

c. Shares any video source immediately with any or all system users

d. Remotely compels a user's device to do specific action (create/share info).

4. RealityVision Screencast (

a. Ad-hoc integration tool that shares complex data such as: 
1) Three-dimensional models, videos, pictures, schematics, Supervisory Control and Data Acquisition data, and so forth.

b. Console operator can select any region of the screen and stream the information as real-time video source:

1) Could be a location, picture, video, or other data placed onto the screen and viewed by other system users.

c. All the data/actions are automatically saved in the RealityVision archive.

\section{Benefits/Features:}

- Understanding events as they happen

- Real-time streaming of videos, GPS tracking, three-dimensional models, schematics, and so forth

- Forensic capabilities

- All data stored (archive video stored as frame-by-frame basis with any text comments, location information, and other metadata)

- Ad-hoc information sharing (Screencast)

- Sharing critical information between any wireless device (e.g., Smart Phones, Golden-i, or PC)

- Enhanced human safety

- See real-time videos and GPS tracking (what's happening and where)

- Secured data distribution

- Is not a social network but a private and secured software (stays inside the company)

- Only authorized users can make any changes to the data (console operator)

- Management console operators may remotely sign off any device at any time (in the event the device is lost or stolen). 